\section{Cancer cachexia and}

\section{fatigue}

Grant D Stewart BSc(Hons) MBChB MRCS(Ed), Surgical Research Fellow

Richard JE Skipworth BSc(Hons) MBChB MRCS(Ed), Surgical Research Fellow

Kenneth CH Fearon MBChB(Hons) MD FRCS(Glas) FRCS(Ed) FRCS(Eng), Professor of Surgical Oncology

Department of Clinical and Surgical Sciences (Surgery), University of Edinburgh, Royal Infirmary, Edinburgh

Clin Med 2006;6:140-3

\section{Background}

Cachexia is a disease process that develops in numerous chronic, end-stage disease processes (eg cancer, heart failure, AIDS, renal failure). It has no agreed definition but represents the complex metabolic process that occurs in patients with these conditions. ${ }^{1}$ Cachectic patients lose lean muscle mass as well as fat, unlike starvation where only fat stores are initially depleted. In addition, the muscle wasting of cachexia cannot be reversed by increased food intake alone., ${ }^{2,3}$ Weight loss is the symptom most commonly associated with cachexia but there are numerous other features (Table 1 ), ${ }^{1}$ of which fatigue is an important one (70-100\% of cancer patients). ${ }^{4}$

Cancer cachexia is common. Half of all patients with cancer lose some body weight; one-third lose more than $5 \%$ of their original body weight and up to $20 \%$ of all cancer deaths are caused directly by cachexia (through immobility, cardiac/ respiratory failure). ${ }^{5}$ Cachexia is particularly prominent in solid tumours of the upper gastrointestinal (GI) tract and lung (Table 2). Weight loss is a prognostic factor in the survival of cancer patients and is associated with a reduced response to chemoradiotherapy. ${ }^{2}$

\section{Pathogenesis}

Cancer cachexia is a complex metabolic disturbance involving numerous mechanisms (Fig 1). The cachectic patient is analogous to an accelerating car running out of petrol. The anorexia component of cancer cachexia reduces fuel supply (by ca $300-500 \mathrm{kcal} /$ day) whilst accelerated metabolic cycling drives hypermetabolism (by ca 100-200 kcal/day). There are also the direct catabolic effects of muscle proteolysis and lipolysis. These changes underlie a key paradox of cachexia: whilst metabolic rate may be increased, overall (or total) energy expenditure is decreased due to a fall in physical activity. ${ }^{7}$

\section{Anorexia}

The anorexia component of cancer cachexia has both a neurohumoral mechanism due to disturbance of the central physiological mechanisms controlling food intake $e^{8}$ and a broad raft of clinical causes. Secondary contributory factors include anxiety, depression, intestinal obstruction, nausea, vomiting, constipation, taste alterations and persistent pain.

\section{Cancer-related fatigue}

The mechanisms of cancer-related fatigue are unclear. Physiological factors leading to fatigue include anaemia, cancer treatments, tumour bulk and cytokine release. Psychological factors such as depression and anxiety, difficulty sleeping and a low degree of physical functioning also contribute. $^{4}$

\section{Other cachectic factors}

Cachexia can occur in the absence of anorexia, suggesting that catabolic mediators produced by tumour or host cells are involved in the cancer cachexia process. ${ }^{9}$ Experimental cachexia models suggest pro-inflammatory cytokines, such as tumour necrosis factor- $\alpha$, interleukin (IL)-6, IL-1 and interferon- $\gamma$, can all play a role. Activation of the neuroendocrine stress response is also thought to be important. Potential mediators include increased adrenergic activity, elevated cortisol, low insulin and increased activity of the renin-angiotensin system. ${ }^{1}$

With regard to tumour-specific cachectic factors, proteolysis-inducing factor (PIF) is produced by tumours and excreted in the urine of patients with cancer cachexia. PIF is thought to contribute to increased muscle breakdown and decreased muscle protein synthesis in such patients. ${ }^{10,11}$ Cachectic cancer patients can also excrete a lipid-mobilising factor which may contribute to depleted adipose tissue and can be detected in their urine. ${ }^{12}$

\section{Diagnosis}

History and examination are the most useful tools in making the diagnosis of cachexia and for assessing response to therapy. Weight loss, anorexia and fatigue are the commonest symptoms reported by advanced cancer patients.
Table 1. Features of cachexia. ${ }^{1}$

- Weight loss

- Anorexia

- Fatigue

- Muscle wasting

- Aesthesia

- Anaemia

- Oedema
Table 2. The commonest malignancies in which cachexia develops as part of the clinical course. ${ }^{6}$

\begin{tabular}{lc} 
Malignancy & $\begin{array}{c}\text { Patients with } \\
\text { cachexia (\%) }\end{array}$ \\
\hline Gastric cancer & 85 \\
Pancreatic cancer & 83 \\
Non-small cell lung cancer & 61 \\
Small cell lung cancer & 57 \\
Prostate cancer & 56 \\
Colon cancer & 54 \\
Unfavourable non-Hodgkin's lymphoma & 48 \\
Sarcoma & 40 \\
Acute non-lymphocytic leukaemia & 39 \\
Breast cancer & 36 \\
Favourable non-Hodgkin's lymphoma & 31
\end{tabular}




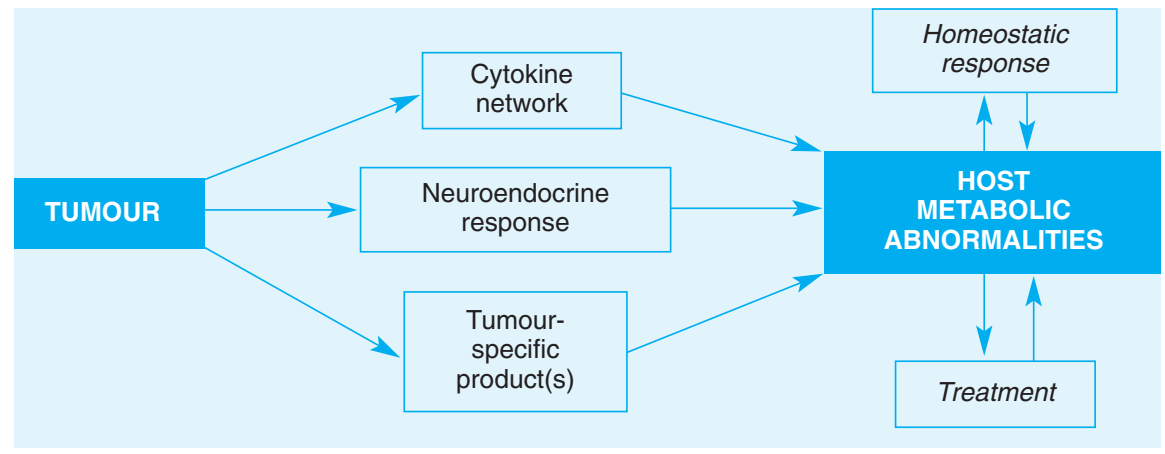

Fig 1. Mediator pathways implicated in cancer cachexia. Different pathways contribute to a variable extent, depending in part on both host and tumour.

Symptoms associated with declining food intake are key warning signals (eg loss of appetite, early satiety, nausea/vomiting and taste/smell alterations). Weight and height should be recorded. Weight loss greater than 5\% suggests developing cachexia, while above $15 \%$ suggests the patient is well advanced into the cachectic state. Body mass index (BMI) should be calculated $(\mathrm{BMI}<18$ indicates significant undernutrition). Oedema and ascites are common, and this fluid retention may mask the severity of underlying weight loss. Plasma albumin concentration may be low and, if accompanied by an elevated C-reactive protein or erythrocyte sedimentation rate, reflects an underlying systemic inflammatory response that occurs in many malignancies and which contributes to the weight-losing process. ${ }^{13}$

\section{Management}

The management of cachexia requires a dedicated multidisciplinary team approach: physician, surgeon, general practitioner, nurse specialist and dietitian. Cachexia is a chronic problem requiring repeated re-evaluation as the clinical condition of the patient changes (Fig 2). Intervention is not usually beneficial for a patient who has become severely wasted, is bedridden and within weeks of dying, but such patients may be helped by a course of steroids to improve mood and appetite. Early recognition and prophylactic measures are better than trying to reverse an advanced situation. Control of the following symptoms will provide the ideal background for optimisation of appetite, function of the GI tract and treatment of the metabolic disorder: ${ }^{1}$

- nausea/vomiting can be controlled with regular anti-emetics (or surgery for mechanical obstruction)

- early satiety is eased by gastric stimulants

- malabsorption is treated with pancreatic enzyme supplements

- constipation is relieved with laxatives

- pain should be controlled with the minimum of sedation

- depression may be treated with antidepressants and counselling.

\section{Diet}

Food intake can be improved by providing small, frequent energy-dense meals that are easy to eat (eg dairy products, ice cream). Patients should eat in pleasant surroundings and attention be given to the presentation of food. Extremes of taste/smell should be avoided, as should meals with very high fat contents (which

\begin{tabular}{|c|c|c|c|c|}
\hline \multirow[b]{2}{*}{ Normal } & \multirow{2}{*}{$\begin{array}{l}\text { Initiating } \\
\text { factors } \\
\\
\\
\text { Mild } \\
\text { cachexia }\end{array}$} & \multicolumn{2}{|c|}{$\begin{array}{c}\text { Compensatory } \\
\text { changes }\end{array}$} & \\
\hline & & $\begin{array}{l}\text { Moderate } \\
\text { cachexia }\end{array}$ & $\begin{array}{l}\text { Severe } \\
\text { cachexia }\end{array}$ & Death \\
\hline $\begin{array}{l}\text { Weight } \\
\text { loss }\end{array}$ & $\begin{array}{l}\text { Below } \\
\text { ideal body } \\
\text { weight }\end{array}$ & $\begin{array}{l}\text { Muscle } \\
\text { wasting } \\
\text { obvious }\end{array}$ & $\begin{array}{l}\text { Reduced } \\
\text { survival }\end{array}$ & \\
\hline
\end{tabular}

Fig 2. The cancer cachexia journey. delay gastric emptying and worsen anorexia). Formal nutritional counselling should be sought from a dietitian. ${ }^{8}$ Provision of energy and protein-dense oral feeds $(1.5 \mathrm{kcal} / \mathrm{ml})$ can be useful, but these must not replace normal food.

One way of optimising nutritional input is for the patient to take a fixed dose of supplements at regular times (as with a prescription medication). Patients should aim to take $200-400 \mathrm{ml}$ of supplements daily (300-600 kcal), accepting that this will suppress some normal food intake but providing an overall gain of 200-400 kcal/day.

\section{Artificial nutritional support}

It is sometimes justified to provide artificial nutritional support (either enteral or parenteral) in advanced cancer patients when the main cause of cachexia is reduced food intake and where limited tumour burden and good performance status justify such invasive forms of supportive therapy. It is at all times important to balance the benefits to a patient's quality of life with the problems of artificial nutritional support (eg time in hospital, complications of central venous access for total parenteral nutrition).

\section{Severe anorexia}

In patients complaining of severe anorexia or early satiety an appetite stimulant may provide symptomatic improvement. Moderate alcohol consumption before and during a meal can help. Early satiety will respond temporarily to the use of prokinetic agents (eg metoclopramide). High doses of progesterones (eg megestrol acetate or 
medroxyprogesterone) improve appetite in about $70 \%$ of patients and can result in increased food intake and weight gain in approximately $20 \% .{ }^{14}$ However, this weight gain is often due to oedema or increased fat deposition rather than skeletal muscle. Together with progestagens, corticosteroids induce a temporary effect on appetite, performance status and the patient's feeling of physical well-being. These changes are limited to a few weeks. Due to the greater toxic side effects associated with corticosteroids, progestagens are the current front-line agents used to treat anorexia in patients with cancer.

\section{Metabolic management}

The metabolic management of patients with cachexia should focus on downregulating the systemic inflammatory response to malignancy. Non-steroidal anti-inflammatory drugs together with peptic ulcer prophylaxis have been shown to prolong survival of cancer patients, reduce systemic inflammation and preserve body fat. ${ }^{13}$ Eicosapentaenoic acid (EPA), a natural component of fish oil, is

\section{Key Points}

\section{Cancer cachexia has no agreed definition but represents a wasting syndrome involving loss of muscle and fat caused directly by tumour factors and/or indirectly by abnormal host response to tumour presence}

Patients with cancer cachexia develop chronic negative energy and protein balance driven by a combination of reduced food intake (secondary to anorexia) and metabolic change

The management of cachexia requires a dedicated multidisciplinary team and is best commenced earlier rather than later

No single or combined treatment strategy will be successful in all patients

KEY WORDS: anorexia, cachexia, cytokines, fatigue known both to downregulate proinflammatory cytokines and to block the effects of tumour-specific cachectic factors (eg PIF). EPA can be provided either as fish oil capsules or as a combination therapy by being incorporated in a high protein and calorie oral feed (eg Prosure ${ }^{\circledR}$ ). This combination has been shown to arrest nutritional decline and improve physical activity levels but not to cause weight gain. ${ }^{7,15}$

Drugs with a direct anabolic effect (eg testosterone) have been suggested for the treatment of cachexia, and anabolic steroids have been shown to improve patients' weight without any apparent adverse effect. ${ }^{1}$

\section{Fatigue}

Management of cachexia as outlined above can improve fatigue. ${ }^{4}$ Decreased activity in order to conserve energy may lead to deconditioning and decreased exercise tolerance. Exercise regimens, such as walking programmes, can reduce the level of fatigue experienced by patients. ${ }^{4}$ Fatigue can also be lessened by attempting to reduce stress and increase psychosocial support. ${ }^{4}$ If fatigue proves a problem or occurs in tandem with anaemia, there is evidence to suggest that recombinant erythropoietin (EPO) may be beneficial. ${ }^{16}$ However, recent evidence has also raised the issue of stimulation of tumour progression with EPO in patients with head and neck cancer. ${ }^{17}$

Finally, it is important to recognise that, although some patients with cachexia can be improved, the goals of intervention are often to stabilise the situation or attenuate decline. Patients should be encouraged to keep active to prevent muscle wasting due to immobilisation. Patients with limited energy reserves/physical activity capacity should be advised to make most efficient use of the energy they have (focusing on meal times and social interaction). Advice from occupational therapy and provision of physical aids in the home may enhance quality of life.

Unfortunately, no single therapy is effective in all patients. Even with optimal management only a proportion of patients will respond to therapy with weight stabilisation and possible translation into stable or improved physical

Table 3. Possible future therapies for cancer cachexia.

\begin{tabular}{|c|c|}
\hline Therapy & Details \\
\hline Cannabinoids (eg dronabinol) & Affect cytokine production \\
\hline Thalidomide & $\begin{array}{l}\text { Stops weight loss in unresectable pancreatic cancer by } \\
\text { downregulating pro-inflammatory cytokines }\end{array}$ \\
\hline Suramin & Inhibits cachexia by inhibition of TNF- $\alpha$ and IL- 6 \\
\hline ATP infusion & $\begin{array}{l}\text { Modestly increases strength and slows decline in quality } \\
\text { of life }\end{array}$ \\
\hline Cytokine traps & Block cytokines (no clinical data yet) \\
\hline Ghrelin & $\begin{array}{l}\text { Appetite stimulant which increases food intake and stops } \\
\text { weight loss in animal models }\end{array}$ \\
\hline Branched chain amino acids & Improve energy levels \\
\hline Dopamine & Increases food intake and mood \\
\hline Melatonin & In combination with fish oils stabilises weight \\
\hline Nitric oxide and eicosanoids & Reduce tumour growth and improve anorexia \\
\hline$\beta$-blockers & $\begin{array}{l}\text { Reduce resting energy expenditure and potentially reduce } \\
\text { weight loss }\end{array}$ \\
\hline ACEls & $\begin{array}{l}\text { Angiotensin II can stimulate muscle breakdown; hence } \\
\text { ACEls can potentially attenuate this weight loss }\end{array}$ \\
\hline $\begin{array}{l}\beta \text {-hydroxy- } \beta \text {-methylbutyrate } \\
\text { plus arginine and glutamine }\end{array}$ & Increases lean body mass \\
\hline
\end{tabular}

ACEI = angiotensin-converting enzyme inhibitor; ATP = adenosine 5'-triphosphate; IL = interleukin;

TNF $=$ tumour necrosis factor. 
function/quality of life. However, the limited benefits of active management are no justification to ignore or fail to treat reversible factors associated with cachexia.

\section{The future}

Over the last decade there has been an explosion of research into the mechanisms of cancer cachexia and potential targets for treatment. Table 3 outlines possible future therapies currently being evaluated. Clinical trials evaluating therapies for cancer cachexia patients are hampered by patient heterogeneity, difficulty in defining end-points, mild to moderate activity of combination regimens, patient attrition and cost. Such problems need to be addressed actively by major research initiatives if there is to be progress in management of this distressing syndrome.

\section{Conflicts of interest}

None.

\section{References}

1 MacDonald N, Easson AM, Mazurak VC, Dunn GP, Baracos VE. Understanding and managing cancer cachexia. Review. J Am Coll Surg 2003;197:143-61.

2 Tisdale MJ. Cachexia in cancer patients. Review. Nat Rev Cancer 2002;2:862-71.

3 Body JJ. The syndrome of anorexiacachexia. Curr Opin Oncol 1999;11:255-60.

4 Ahlberg K, Ekman T, Gaston-Johansson F, Mock V. Assessment and management of cancer-related fatigue in adults. Review. Lancet 2003;362:640-50.

5 Tisdale MJ. Biology of cachexia. Review. J Natl Cancer Inst 1997;89:1763-73.

6 DeWys WD, Begg C, Lavin PT, Band PR et al. Prognostic effect of weight loss prior to chemotherapy in cancer patients. Eastern Cooperative Oncology Group. Am J Med 1980;69:491-7.

7 Moses AW, Slater C, Preston T, Barber MD, Fearon KC. Reduced total energy expenditure and physical activity in cachectic patients with pancreatic cancer can be modulated by an energy and protein dense oral supplement enriched with n-3 fatty acids. Br J Cancer 2004;90:996-1002.

8 Laviano A, Meguid MM, Rossi-Fanelli F. Cancer anorexia: clinical implications, pathogenesis, and therapeutic strategies. Review. Lancet Oncol 2003;4:686-94.

9 Beck SA, Tisdale MJ. Production of lipolytic and proteolytic factors by a murine tumor-producing cachexia in the host. Cancer Res 1987;47:5919-23.

10 Lorite MJ, Cariuk P, Tisdale MJ. Induction of muscle protein degradation by a tumour factor. Br J Cancer 1997;76:1035-40.

11 Wigmore SJ, Todorov PT, Barber MD, Ross JA et al. Characteristics of patients with pancreatic cancer expressing a novel cancer cachectic factor. Br J Surg 2000;87:53-8.

12 Hirai K, Hussey HJ, Barber MD, Price SA, Tisdale MJ. Biological evaluation of a lipid-mobilizing factor isolated from the urine of cancer patients. Cancer Res 1998;58:2359-65.

13 Deans C, Wigmore SJ. Systemic inflammation, cachexia and prognosis in patients with cancer. Review. Curr Opin Clin Nutr Metab Care 2005;8:265-9.

14 Maltoni M, Nanni O, Scarpi E, Rossi D et al. High-dose progestins for the treatment of cancer anorexia-cachexia syndrome: a systematic review of randomised clinical trials. Ann Oncol 2001;12:289-300.

15 Fearon KC, Von Meyenfeldt MF, Moses AG, Van Geenen R et al. Effect of a protein and energy dense N-3 fatty acid enriched oral supplement on loss of weight and lean tissue in cancer cachexia: a randomised double blind trial. Gut 2003;52:1479-86.

16 Rizzo JD, Lichtin AE, Woolf SH, Seidenfeld $\mathrm{J}$ et al. Use of epoetin in patients with cancer: evidence-based clinical practice guidelines of the American Society of Clinical Oncology and the American Society of Hematology. J Clin Oncol 2002; 20:4083-107.

17 Henke M, Laszig R, Rube C, Schafer U et al. Erythropoietin to treat head and neck cancer patients with anaemia undergoing radiotherapy: randomised, double-blind, placebo-controlled trial. Lancet 2003;362: 1255-60. 